\title{
APPLICATION OF GEOGRAPHIC INFORMATION SYSTEMS FOR FLOOD RISK ANALYSIS: A CASE STUDY FROM ACCRA METROPOLITAN AREA
}

\begin{abstract}
Alex Barimah Owusu ${ }^{1}$, Mathias Agbozo ${ }^{1}$
Key words: Geographic Information Systems, Flooding, Flood Risk Zones, Accra Metropolitan Area.

Abstract. The main objective of the study was to identify high flood risk zones in AMA. The study also used questionnaires to assess local knowledge on what accounts for the high flood risk in their community. Spatial analysis techniques were used to model flood risk based on the following contributory factors; land cover, soil, drainage density, topography and proximity to rivers. The results show that high flood risk areas covered $46.3 \mathrm{~km}^{2}(20 \%)$, moderate risk area, $72.9 \mathrm{~km}^{2}(31.6 \%)$, low risk area $41.5 \mathrm{~km}^{2}(18 \%)$ and very low risk areas, about $6.7 \mathrm{~km}^{2}(2.9 \%)$. The high flood risk zones were low-lying areas below 50 meters above sea level and closely associated with poor drainage systems. People perceived not just low-lying areas as a paramount reason accounting for flooding but also very bad waste disposal habit of the public. These offsets the efforts of waste management companies to keep drains free of refuse.
\end{abstract}

\section{Introduction}

Over the past 20 years, natural disasters have resulted in the death of at least 3 million people worldwide and have adversely affected nearly 800 million people (Hosseni and Mehdiyar, 2006). According to Smith (2004) "flooding is the most common environmental hazard worldwide, after disease and transport accidents. This has been attributed to factors such as the widespread geographical distribution of river floodplains and low-lying coasts and their long-standing attractions for human settlement. On yearly basis, 20,000 lives are lost to floods and at least 20 million people worldwide are negatively affected, by being rendered homelessness. Ghana like many other countries of the world, is vulnerable to this form of natural disaster because of some geophysical characteristics: including elevation and drainage system; socio-economic factors including settlement patterns and poverty and other ecological factors. Some areas in Ghana including parts of Accra and

\footnotetext{
${ }^{1}$ Department of Geography and Resource Development, University of Ghana, LG 59, Legon, Accra, Ghana, West Africa; owusuba@yahoo.com
} 
northern Ghana appear to be the most flood prone. Flooding in Ghana is primarily perennial in nature occurring yearly in the raining season, April to October and worsening during the peak of the rainfall season in May/June at the southern half of the country and in August/September in the north part of the country. This results in adverse consequences such as loss of human lives, farm lands and livestock as well as loss of other properties and outbreak of diseases among others. It is estimated that the cost of damage of floods in Ghana was more than one million US dollars during the 2008 fiscal year (Karley 2009). Notwithstanding, some efforts have been made by city authorities to address flood issues within Accra

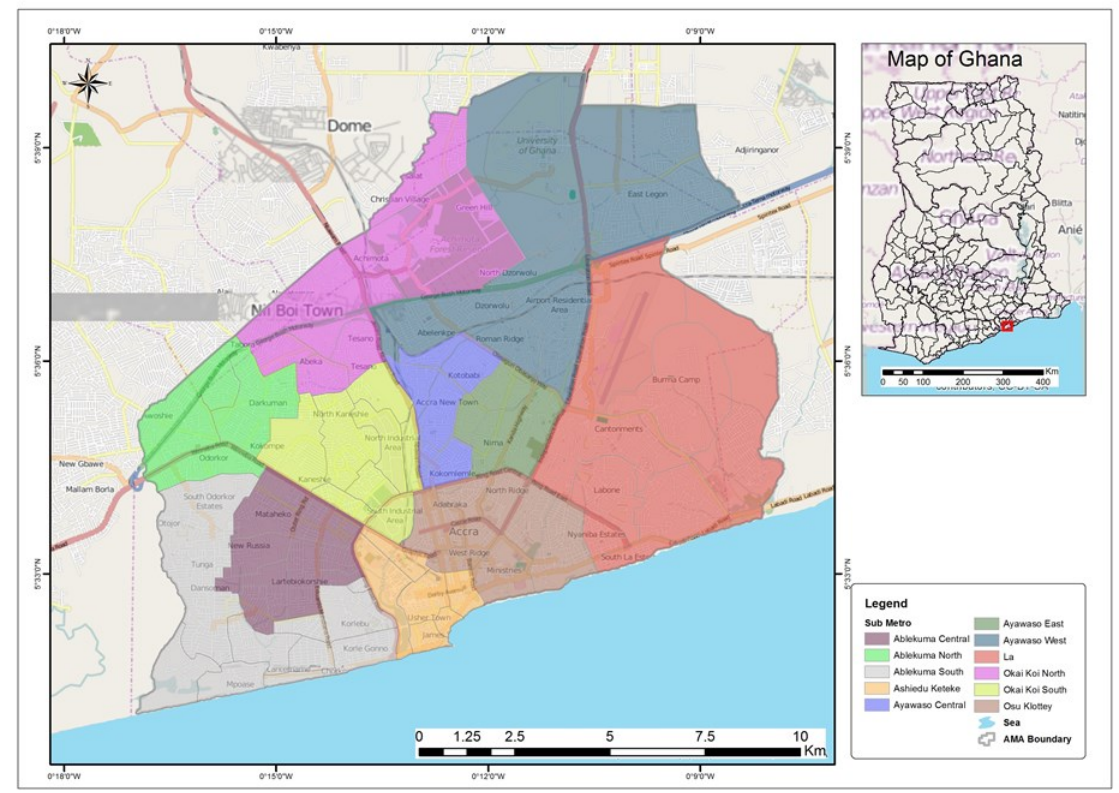

Figure 1: Location Map of Study Area

Metropolitan Area (AMA) by cleaning gutters, removing unauthorized structures, widening of gutters and establishment of sanitation courts to prosecute flouters of sanitation regulations. One such exercise to address perennial flooding was dubbed; "removal for development" under which structures on waterways were demolished, debris conveyed and storm drains reconstructed in 2012 fiscal year. In as much as city authorities have vowed to end flooding in the city, floods persist and continue to cause havoc in AMA. In the light of the devastating consequences, this research attempted to generate the geospatial pattern of flood risk by using spatial analytical techniques to answer the following questions: 
a. Where are the high flood risk zones in AMA?

b. What account for the risk in these areas?

c. What are the communities in these zones doing about their flooding situation?

The study was conducted in the AMA. AMA has a total land surface area of approximately $231 \mathrm{~km}^{2}$ and lies in the Coastal Savannah zone. The metropolitan area experiences bi-modal rainfall with a mean annual rainfall of about $730 \mathrm{~mm}$. The rainfall regime can be categorized as the main season which begins in April and ends in July, and then, a minor dry season in August before the minor rainy season starts in September and ends in November. The major dry season begins in late November and ends in March.

The total population of AMA is about 1,848,614 (GSS, 2013). However, the catchment area of AMA extends beyond its present boundary, creating an urban sphere of influence which commands a burgeoning population of over 5million people and which is growing at an estimated rate of $4.2 \%$ per annum since 2002 (AMA 2014). The Metropolitan area consists of eleven sub-metros as shown in the study area map in Figure 1. The sheer population size and the magnitude of economic activities in AMA create greater concern for city authorities and it is therefore not surprising that an estimated $34 \%$ of the city's daily waste goes uncollected and majority of that ends up in major drains (AMA 2015).

\subsection{Floods and Flood Risk Assessment}

Flooding is a hydrological phenomenon characterized by both precipitation and soil-water contribution and can lead to disastrous consequences including the loss of lives and property. The nature and effects of floods have led to many studies being conducted to assess the causes, impacts and risks of flooding all over the world. Dhār and Nandargi (2001) have described flooding as the most catastrophic, frequent and widespread disaster in the world, while Askew (1999) points out that among all-natural disasters, floods have caused about one-third of all deaths, injuries and damages.

In Africa, Baffoe-Bonnie, et.al (2006) highlight flooding as the most frequent and destructive disaster, responsible for loss of lives, severe damages to property and the spread of disease such as malaria, dengue fever and cholera. Between 1900 to 2006 , about 20,000 people in Africa were killed by floods, about 40 million more were severely affected, while the total cost of damages about US\$4 billion (Mulungeta et al., 2007).

Rainfall is one the major causes of floods all over the world. In recent times, rainfall is erratic and unpredictable, according to Nethler (2012), making it difficult to give predictions on the amount, duration and intensity of rainfall and possible occurrence of floods for any season. During rainy seasons, Wurtermberger et al (2011) indicate that various rivers and streams over flow their banks due to the 
increase in water volume caused by rainfall. Duivendijk (1999) explained that floods result from precipitation, causing volume of water to reach a peak stage that cannot be discharged easily when it enters a given basin/sub-basin area. He further points out that, time of concentration and area are two critical elements to consider because the volume of water that causes floods is too great for aquifers to absorb within a brief period, and evaporation also takes a while.

Climate change and global warming are also directly related to the occurrence of floods in the world, with the earth getting warmer due to high volumes of greenhouse gases entering the atmosphere (Attipoe, 2014). According to Hofmann et al., (1998) climate change may cause differences in oceanic and atmospheric circulation, which also affect temperature and precipitation. Variations in temperature and precipitation however, together with the effects on evapotranspiration and soil moisture, can result in relatively substantial changes in the magnitude and timing of runoff and the intensity of floods.

Although a natural phenomenon, certain anthropogenic activities further worsen the effects of flooding in urban areas including deforestation, (Andjelkovic, 2001), urbanization, (Diop, 2000), building in waterways and poor drainage, (Chan, 1997). Jha et. al (2012), and Danquah (2013) also add more information to the discourse that, floods are a result of the overflow of dams, or of the failure artificial water systems. They also articulated the importance of location characteristics such as elevation and differences in the extent and degree of human modification of a place. Location characteristics arguably encompasses flood causing factor as they all manifest in differences in location. As such efforts at addressing flood vulnerability starts with one basic step of answering the question; who is at risk? Answering this question may require the creation of flood risk maps; which form the basis of decision-making (Kwang and Osei, 2017). The use of satellite imagery has been useful in mapping features on the Earth surface and studying environmental processes and change (Ikusemoran, 2009). Creating flood risk maps can provide descriptive information on the nature and impacts of flooding and can assist decision makers, engineers and planners in making the right decisions and in taking the appropriate steps for dealing with flood related issues. The use of remote sensing and GIS techniques help integrate spatial data as well as data from other sources, into a single system. They help users to manipulate and display spatial information with interactive maps that contain different layers of information; making them essential tools in flood risk and vulnerability analysis. Uddin et.al (2013), stated that geospatial technology is the best tool for analysis, to produce timely and effective results required for decision-making on flood. They further state that, remote sensing is an efficient tool for flood mapping and suitability analysis and can be useful for emergency response and disaster 
preparedness. It is against this background that this study was undertaken in the AMA to assess the spatial pattern of flood risk.

\section{Methodology}

\subsection{Data Collection}

The primary data for this research were gathered from questionnaires administered in identified high flood risk areas which helped ascertain information on what accounts for the high flood risk. In addition, three Focus Group Discussions (FGDs) were held at three separate communities considered high, medium and low risk communities within the study area. It also included Global Positioning Systems (GPS) location data of interviewed high flood risk households which was collected using a GPS device to validate their location and the GIS data as well as proximity to river and drainage density data generated using ArcGIS software.

Secondary data for the study was gathered from books, journals and articles of research on flood risk mapping, flood hazard mapping and flood management accessed through libraries and the internet. Other secondary data were the various GIS data used for spatial analysis as listed in the table.

Table 1: Spatial data, type and source

\begin{tabular}{|c|c|c|c|c|c|}
\hline & Data & Type & Source & Resolution & Accuracy \\
\hline 1. & $\begin{array}{l}\text { Digitized boundary, } \\
\text { roads and towns }\end{array}$ & Shapefile & $\begin{array}{l}\text { RS/GIS lab, } \\
\text { university of } \\
\text { Ghana }\end{array}$ & - & $95 \%$ \\
\hline 2. & $\begin{array}{c}\text { Elevation/slope } \\
\text { (Digital Elevation } \\
\text { Model) }\end{array}$ & Raster & CERGIS & $90 \mathrm{~m}$ & $95 \%$ \\
\hline 3. & Land cover data & Shapefile & $\begin{array}{l}\text { RS/GIS lab, } \\
\text { University of } \\
\text { Ghana }\end{array}$ & $90 \mathrm{~m}$ & $85 \%$ \\
\hline 5. & $\begin{array}{l}\text { Drainage data } \\
\quad \text { (rivers) }\end{array}$ & Shapefile & $\begin{array}{l}\text { RS/GIS lab, } \\
\text { university of } \\
\text { Ghana }\end{array}$ & $90 \mathrm{~m}$ & $85 \%$ \\
\hline 6. & Soil data & Shapefile & $\begin{array}{l}\text { RS/GIS lab, } \\
\text { university of } \\
\text { Ghana }\end{array}$ & $90 \mathrm{~m}$ & $85 \%$ \\
\hline 7. & $\begin{array}{c}\text { Proximity to water } \\
\text { body data }\end{array}$ & Raster & Generated & $90 \mathrm{~m}$ & - \\
\hline 8. & Drainage Density & Raster & Generated & & - \\
\hline
\end{tabular}




\subsection{Population, Sample Size and Technique}

The population considered for the questionnaire interviews were the residents (households and shops) located within the identified high flood risk areas of the study area. This study used multistage cluster sampling method. First the area was classified and sampled into high, low and medium risk areas. Secondly some five high risk clusters were randomly sampled and finally within the five localities another simple random sampling was performed to select some households for the administration of questionnaires. The method was suitable since they were small communities where house numbers could be obtained, making sampling representative and unbiased. The sample size of this study was 100 . It is important to state on record that although questionnaire interviews were conducted only in selected high-risk communities, the views of residents of low and medium risks communities were solicited through focus group discussions and were used in support of some of the arguments and conclusion in the study.

\subsection{Data Analysis}

The analysis was done in two phases; preparation of indicator-based maps and compilation of flood risk map. In the GIS analysis, indicators analyzed were: elevation, land cover, soil and drainage. These indicators have been further highlighted in the next section. A map was then produced based on selected indicators. The indicator-based maps were overlaid to produce a composite map; the flood risk map showing areas within Accra Metropolitan Area and the flood risk levels.

The primary data which were collected with questionnaires were analyzed using descriptive statistics, and the SPSS software was used in generating the descriptive statistics that were presented in graph and bar charts. Similarly, the recorded discussions from the FGD were analyzed qualitatively and used in support of other data analysis to arrive at the conclusions made in the study.

\section{Results from the analysis of indicators}

\subsubsection{Elevation}

Elevation plays a significant role in terms of its effect on the contribution of rainfall to stream flow. It influences the duration of overland flow, infiltration and sub-surface flow. Naturally, areas with high elevation are less liable to flooding than low lying grounds which are normally valleys and highly susceptible to floods (Jha et. al 2012; Danquah 2013). Surface with a lower elevation has a higher risk because it is easier to be inundated by flood. Floods occur only in higher elevation areas where the flow channels are obstructed. Digital Elevation Model data, which was an Shuttle Radar Topography Mission (SRTM) data of 90 meters spatial resolution was clipped and analyzed, assigning weight to five classes to show the terrain of the study area. The assignment of weight was done by two experts from the Environmental Protection Agency (EPA) of Ghana. The classes and their 
weights are shown in Table 2 and the prepared map in figure 2. The class weight is the indicator contribution to flooding. On the scale of $1-5$, with 5 contributing the highest, the elevation data was classified based on Jenkin's natural breaks. The areas classified have elevation less than 70 meters above sea level. Their high-risk level as classified by EPA experts may have also been partly due to experience with communities that have suffered floods. The results of the elevation classes and the weighted contribution are presented on table 2 .

Table 2: Elevation data classification and weight

\begin{tabular}{ccc}
\hline Class & Elevation (meter) & Weight \\
\hline $\mathbf{1}$ & $0-69.473$ & 5 \\
$\mathbf{2}$ & $69.44-137.06$ & 4 \\
$\mathbf{3}$ & $137.07-217.80$ & 3 \\
$\mathbf{4}$ & $217.81-307.93$ & 2 \\
$\mathbf{5}$ & $307.94-478.79$ & 1 \\
\hline
\end{tabular}

\subsubsection{Soil Type}

Soil type influences the level of flooding by determining the rate of infiltration, percolation and hydraulic conductivity. The soil type of an area is important as it controls the amount of water that can infiltrate into the soil, and hence the amount of water which becomes flow (Nicholls and Wong, 1990). When water is supplied at a rate that exceeds the soil's infiltration capacity, it moves down slope as runoff on sloping land, and can lead to flooding (Lowery et al., 1996). The soil data acquired helped determine various soil types as Luvisols (Soil A) Plinthosols (Soil B) and Acrisols (Soil C) based on their properties. The soil data in a form of polygon shapefile was converted into raster using the Polygon to Raster tool and was resampled from 30 meters to 90 meters resolution. Furthermore, it was classified with assigned weight on the grounds of their susceptibility to infiltration indicated in Table 3, using expert knowledge from EPA. The prepared map is shown in Figure 3. The study of soil properties indicates that soil type C (Acrisols) is more susceptible, followed by type B (Plinthosols) while type A (Luvisols) is the least susceptible.

Table 3: Soil Types

\begin{tabular}{ccc}
\hline Class & Soil type & Weight \\
\hline $\mathbf{1}$ & A & 1 \\
$\mathbf{2}$ & B & 2 \\
$\mathbf{3}$ & C & 3 \\
\hline
\end{tabular}




\subsubsection{Land Cover}

Land cover types have principal influence on run-off generation through the combination of high hydraulic conductivity, high surface cover and surface roughness value with agricultural areas generating high rates of surface run-off than natural vegetation areas (Prachansri, 2007). Land cover data in the form of vector was converted into raster data and further resampled to a resolution of 90 meters. Land cover types include Shrub thicket with or without trees, Grass/herb with or without trees, Settlement and Lagoon. It was reclassified assigning highest weight to the land cover type likely to generate more run-off (lagoon) and the least weight to the land cover type likely to generate least run-off (Shrub thicket with or without trees). Like other data used, the assignment of weight for land cover types was done by two experts from EPA, Ghana. Land cover map prepared is shown in Figure 4.

Table 4: Land Cover Types

\begin{tabular}{clc}
\hline Class & \multicolumn{1}{c}{ Land cover type } & Weight \\
\hline $\mathbf{1}$ & Shrub thicket with or without trees & 1 \\
$\mathbf{2}$ & Grass/herb with or without trees & 2 \\
$\mathbf{3}$ & Settlement & 3 \\
$\mathbf{4}$ & Lagoon & 4 \\
\hline
\end{tabular}

\subsubsection{Proximity to Rivers}

Water bodies shapefile was joined with town data shapefile of the study area. This gives the distance of every town from the nearest river or water body. Inverse Distance Weighted (IDW) tool was used to interpolate a raster surface using distance to the nearest water body as the $\mathrm{z}$ value. The output which is the raster data showing distance to nearest water body was reclassified assigning more weight based on distance to nearest river as shown in Table 5 and output map in Figure 5. The raster data was resampled to 90 meters resolution while the weight was assigned by experts from EPA supported by local knowledge of areas that have experienced floods in the past.

Table 5: Proximity to Rivers

\begin{tabular}{ccc}
\hline Class & Distance (meter) & Weight \\
\hline $\mathbf{1}$ & $21.030-418.035$ & 5 \\
$\mathbf{2}$ & $418.035-695.939$ & 4 \\
$\mathbf{3}$ & $695.939-1083.020$ & 3 \\
$\mathbf{4}$ & $1083.020-1569.352$ & 2 \\
$\mathbf{5}$ & $1569.352-2551.941$ & 1 \\
\hline
\end{tabular}




\subsubsection{Drainage Density}

River shapefile was first clipped to the study area. The output shapefile was then used as input feature for a density analysis which made use of kernel density tool. Density analysis was performed to examine the distribution of rivers in AMA. A watershed with adequate drainage should have a drainage density $\geq 5 \mathrm{~km} / \mathrm{km} 2$, while the moderate and the poor ones have a drainage density of $1-5 \mathrm{~km} / \mathrm{km} 2$ and $<1 \mathrm{~km} / \mathrm{km} 2$ respectively (Chankao, 1982) and confirmed by two (2) EPA experts. High density areas were assigned high weights and less density areas with less weight as shown in Table 6 and the map generated is shown in Figure 6.

Table 6: Drainage Density

\begin{tabular}{ccc}
\hline Class & Area (square kilometers) & Weight \\
\hline $\mathbf{1}$ & $0-1.632$ & 1 \\
$\mathbf{2}$ & $1.632-4.569$ & 2 \\
$\mathbf{3}$ & $4.569-8.934$ & 3 \\
$\mathbf{4}$ & $8.934-19.233$ & 4 \\
$\mathbf{5}$ & $19.233-39.727$ & 5 \\
\hline
\end{tabular}

\subsubsection{Flood Risk Map}

The total weight for estimating the probability of flooding in a flood hazard zone is equal to the sum of every contributing factor (Pramojanee et al., 1997). The final flood risk map was compiled by combining all the indicator-based maps into one. The various reclassified risk indicator maps were combined using the weighted overlay tool indicating the level of influence of each indicator. Prior to composing the final map, factor contribution was determined using opinions from two sources. First, EPA Experts were asked to assign weight to the variables. Secondly, the participants of the three FGDs were asked to rank these factors in terms of their importance in contributing to floods. These two groups of people ranked the factors. A level of influence of 30, 25, 20, 15 and 10 percent were assigned to elevation, land cover, soil, proximity to rivers and drainage density indicators respectively to arrive at the individual factor risk map. The individual factor risk map was reclassified and ramped into a scale from high to low. The final flood risk map was an addition of all factor risk maps using raster calculator in the ArcGIS software. Below are summary of individual indicator risk maps showing locations of high risk for each indicator. 


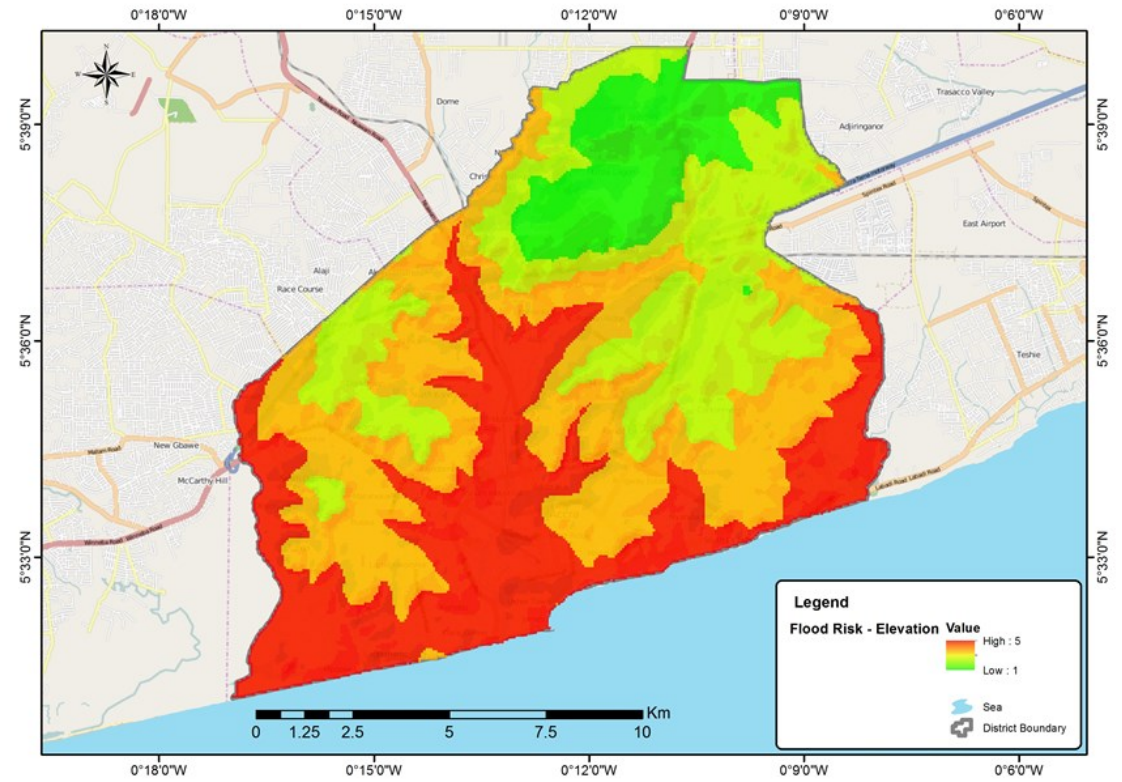

Figure 2: Digital Elevation Model Map

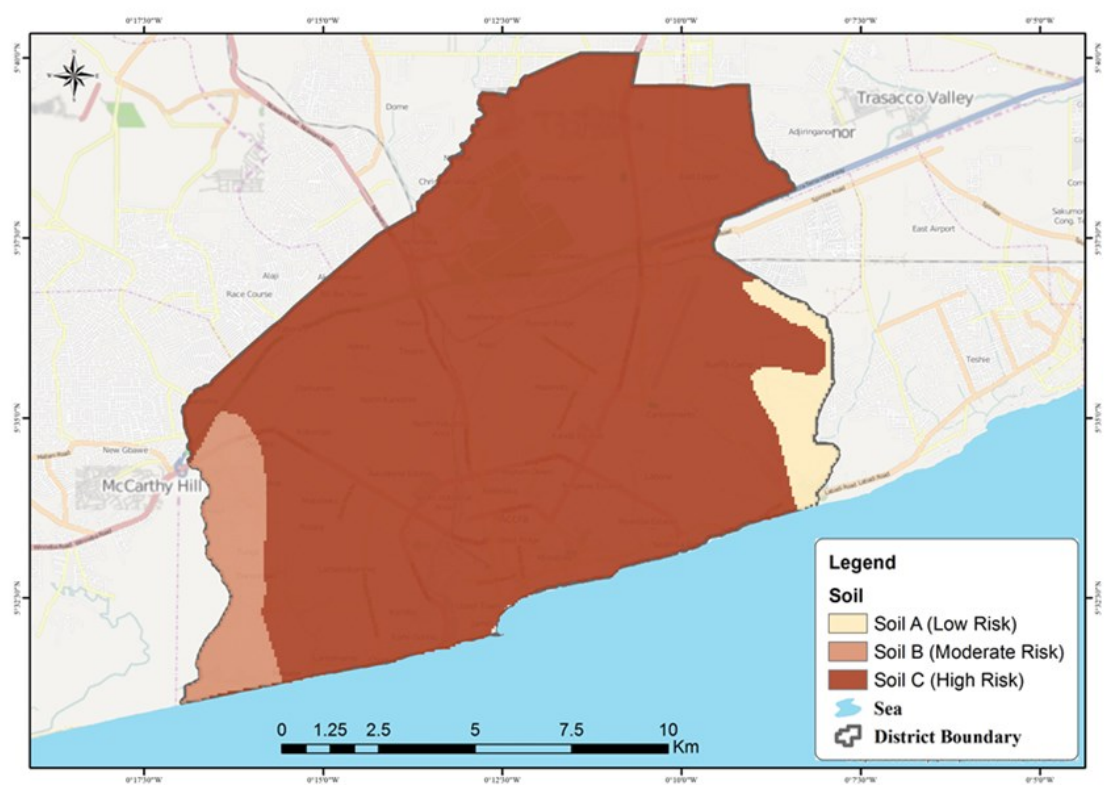

Figure 3: Soil Map 


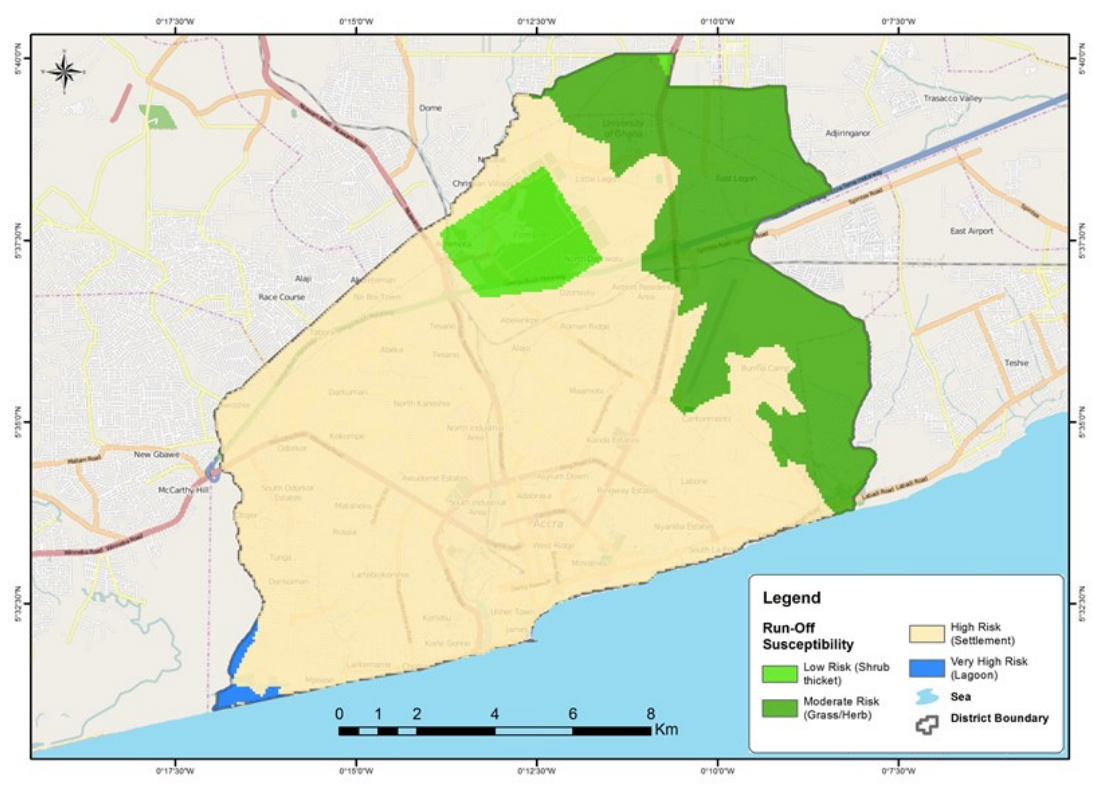

Figure 4: Land Cover Map

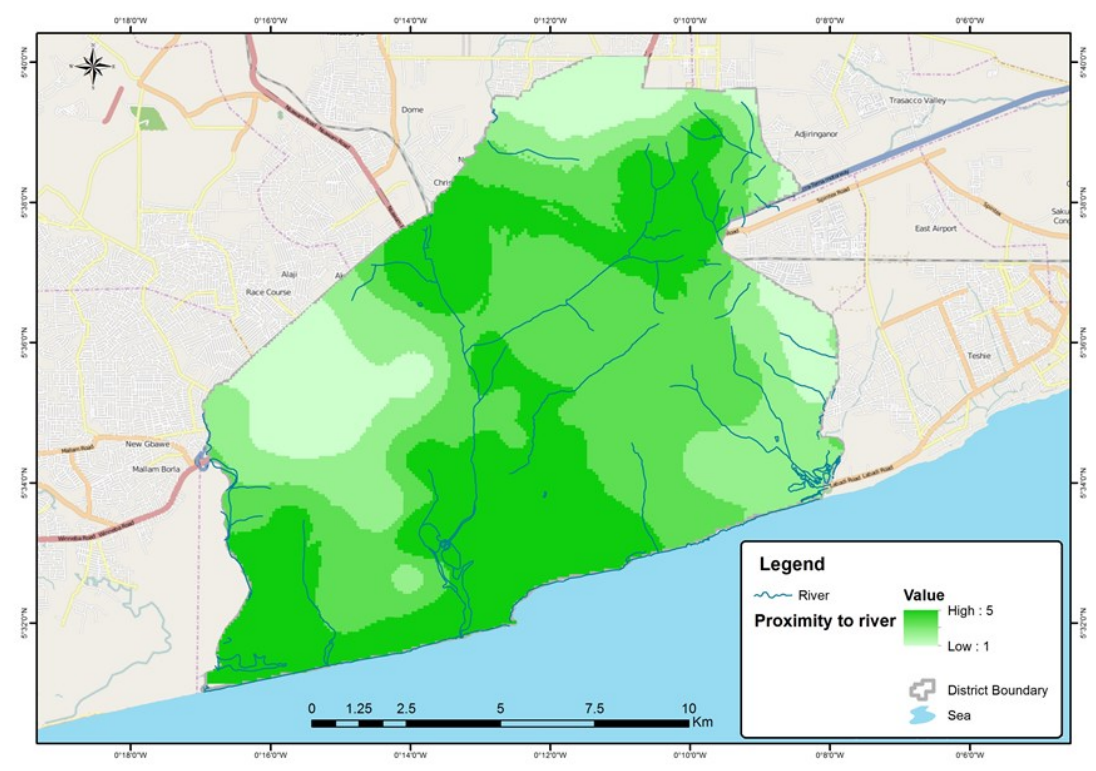

Figure 5: Proximity to River 


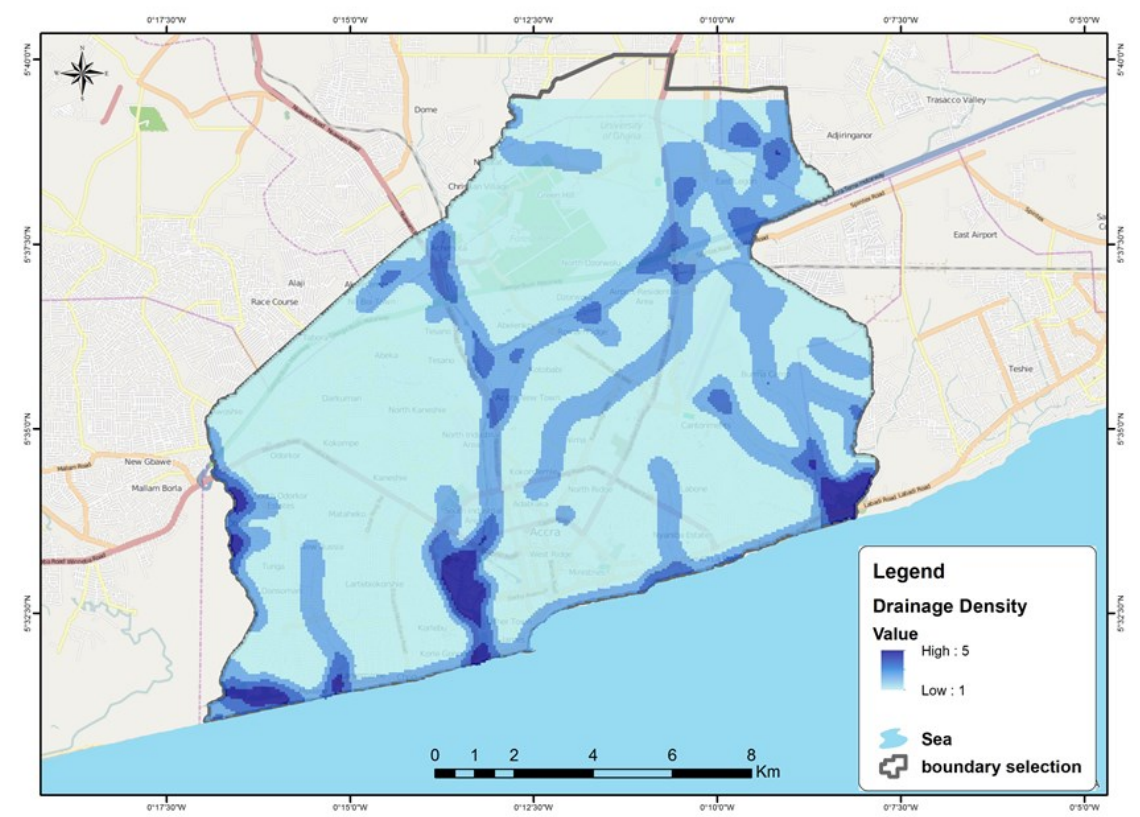

Figure 6: Drainage Density Map

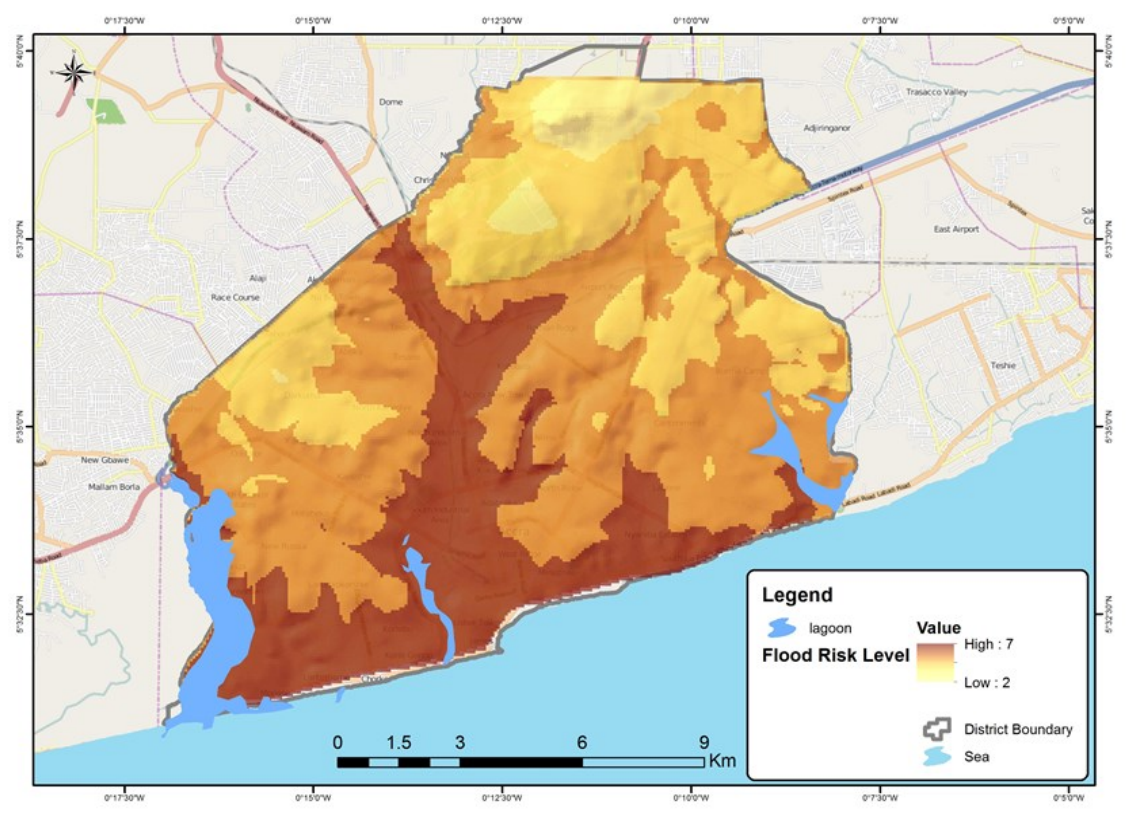

Figure 7: Flood Risk Map 
The final risk map which is a composite map of all indicators is shown in figure 7. The final map shows that the high flood risk areas are found in the southern (along the coast) and central portions of AMA where it is mostly low lying within major drainage basin. It is estimated that high flood risk areas cover approximately $46.3 \mathrm{~km}^{2}$ roughly $20 \%$ of the area. Also, about $72.9 \mathrm{~km}^{2}$ of land area is classified as moderate flood risk area and this covers about $31.6 \%$ of AMA land area whiles $41.5 \mathrm{~km}^{2}(18 \%)$ and $6.7 \mathrm{~km}^{2}(3 \%)$ area classified as low risk area very low risk areas respectively. The high-risk areas are all low-lying areas with elevation of less than 50 meters above sea level.

\subsection{Factors that account for flooding in the study area}

For validating the spatial analysis performed with GIS data, the study sought the opinion of residents on the occurrence of flood and what might account for the frequent flooding in their community. Data gathered as shown in Figure 8 also indicate that $13 \%$ of respondents indicating occurrence of flood in the community and attributed major cause of flooding to building in water ways, another $31 \%$ attributed to bad refuse disposal mostly into drains. Only $4 \%$ and $16 \%$ however associated flooding in their vicinity to poor design of drains and choked drains respectively. Majority of respondents, 36\% linked almost annual flooding experiences to the low-lying relief of their locations. Figure 8 depicts residents' response to causes of flooding in their community.

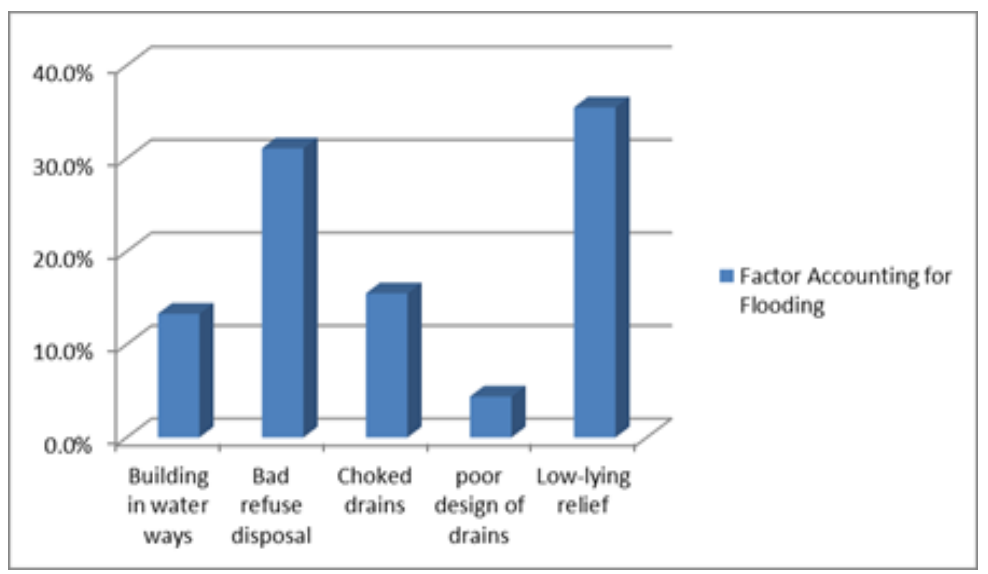

Figure 8: Factors Accounting for Flooding

From figure 8, the primary cause of flooding in their communities is low elevation (low-lying relief), followed by about 30\% respondents attributing 
flooding to bad or poor refuse disposal. It is however worth noting that, poor refuse disposal may or may not lead to choked gutters, whiles choked gutters may or may not be caused by poor refused disposal. In the case of flooding, poor refuse disposal contributes by choking gutters and drains thereby preventing run-off from flowing freely. Residents acknowledged that efforts have been made by the Metropolitan Assembly to combat floods popularly with respect to choked drains and buildings in water ways where existing storm drains received routine maintenance and clean-up exercises to ensure that choked gutters are cleaned as well as the demolition of structures in waterways.

\subsection{Community Effort}

Collective community effort was something that most of these flood prone areas were not so much involved in. Figure 9 shows that, $64 \%$ of respondents affirm that absolutely no community effort has been embarked on in these places. Another $36 \%$ said otherwise, that some efforts have been made in their community to prevent flooding. Among the $36 \%$, about $85.7 \%$ purported that these community efforts have been in the form of desilting gutters.

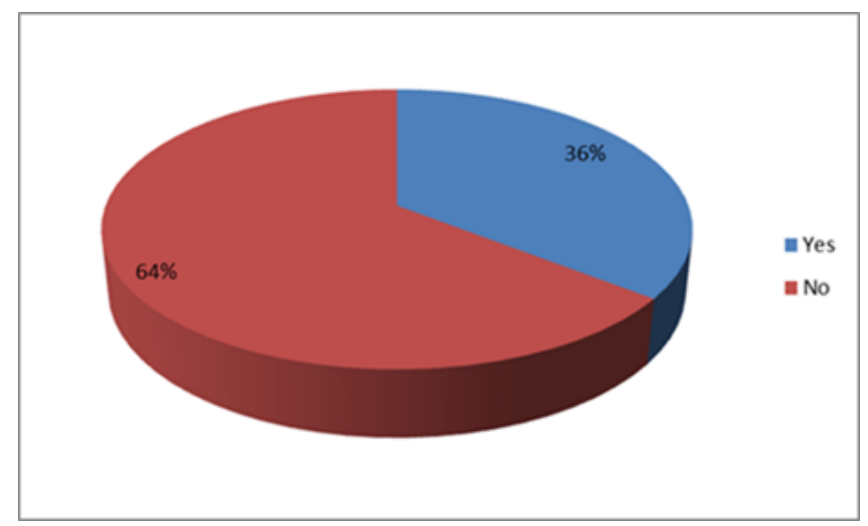

Figure 9.Community Effort

\section{Conclusion}

In conclusion, this study shows a simple way of using Geographical Information Systems for modeling flood risk using spatial data. It was identified that high flood risk areas covered $46.3 \mathrm{~km}^{2}(20 \%)$, moderate risk area $72.9 \mathrm{~km}^{2}(31.6 \%)$, low risk area $41.5 \mathrm{~km}^{2}(18 \%)$ and very low risk areas being about $6.7 \mathrm{~km}^{2}(2.9 \%)$ with most high flood risk zones being very low-lying areas below 50 
meters. Flood prone areas in most cases in these low-lying areas are, however, closely associated with drainage systems which are poorly drained results in the inability of run-off to flow easily to safe grounds. Examples of Communities within this zone are Nima, Alajo and Circle. Again, notwithstanding the fact that relief is the main factor accounting for flooding, bad refuse disposal (that is most people using primary and secondary drains as waste receptacles) has contributed immensely to the perennial flooding associated with these communities. Perhaps the most critical concern is the community insensitivity to the flooding that has saddled their neighborhoods. Communities affected by floods in AMA have over the years questioned Government and City Administrators response to their plight, while ignoring the need for community effort to maintain proper sanitation, including household level waste management. It is evidently clear that Community effort has been at the low side with most communities doing virtually nothing about it and awaiting government intervention. It be partly true that the geographic positioning of AMA, as defined by the elevation, drainage system and proximity to the sea has made flooding inevitable, however, the flood susceptibility has been exacerbated by human activities, including haphazard citing of facilities, poor drainage construction and maintenance and above all improper disposal of waste which leads to choked gutters. It is therefore recommended that the three (3) key stakeholders (City Authorities, Residents and Local Businesses) may need to collaborate to leverage their efforts and resources to effectively reduce the flood vulnerability if not completely eliminate it. These stakeholders include the City authorities issuing building permits, taking taxes from businesses and managing the city and its physical planning; the Communities themselves who live and generate the waste, while creating the physical structures; and finally, businesses operating within these communities, especially those who manufacture polythene bags. These stakeholders need clearer understanding that they all have contributed partly to the problem and therefore have a role to play in solving the problem. The City authorities need to examine its permits for construction and also reconsider their designs for construction of drains including drain size, drain structure, either covered or uncovered drain and location of business including building on water ways. Businesses need to examine the technology used to produce biodegradable and recyclable polythene as well as paying for the cost of cleaning the environment. Local communities share of the blame lies in their own construction activities, including infilling and building of attachments to existing buildings which usually extends to drains. They need education on proper waste management at the household level and better ways of disposing waste without dumping in drains. Above all, communities need to organize communal activities that will support government efforts at ensuring choke free drains in the communities. 
This study used spatial data collected and ArcGIS software in modeling flood risk in AMA. As much as GIS may be useful in flood risk mapping, there are some limitations and may not be $100 \%$ accurate. The study therefore recommends that any initiative of organizations or government to address flood issues should be taken in consultation with the people living in the identified areas as well as further thorough assessment on the ground.

\section{References}

Accra Metropolitan Assembly (AMA), (2015). Sanitation and Environment. http://www.ghanadistricts.org/districts/?r=1\&_=3\&sa=3027\# (04/02/2015)

Andjelkovic, I., (2001), Guidelines on Non-Structural Measures in Urban Flood Management. Paris.

Askew, A.J. (1999). Water in the International Decade for Natural Disaster Reduction. In: Leavesley et al (Eds) Destructive Water: Water-caused Natural Disaster, their Abatement and Control. IAHS Publication, 239.

Attipoe, S.K (2014). An Assessment of Flood Mitigation Measures in Accra, Ghana. (Master's Thesis). Kwame Nkrumah University of Science and Technology (KNUST), Kumasi, Ghana.

Baffoe-Bonnie, B. Yeboah, F.A, Buabeng S.N, Ofori, A. and Collins A. (2006). Human Health Vulnerability and Public Health Adaptation to Climate Change: Risks and Responses Assessment Report, Government of Ghana Environment Protection Agency Netherlands Climate Assistance Programme (NCAP).

Chan, N. W. (1997). Increasing flood risk in Malaysia: Causes and Solutions. Disaster Prevention and Management, Vol. 6, pg.72-86.

Chankao K. (1982). Principle of Watershed Management, Faculty of Forestry, Kasetsart University, Bangkok, Thailand.

Danquah, I.O., (2013) "Climate Change and its impacts on flooding in Accra- Greater Accra Metropolitan Assembly”, MSc. Thesis, Kwame Nkrumah University of Science and Technology, Kumasi.

Dhar, O. N, Nandargi S. (2001). A comparative flood frequency study of Ganga and Brahmaputra river systems of north India - a brief appraisal. Water Policy 3: 101107.

Diop, M.B., (2000), Problems Associated with Flooding in Dakar, Western Senegal: Influence of Geological Setting and Town Management. Bull Eng. Geol Env, Vol. 58, pp.145-149.

Duivendijk J. V., (1999), Assessment of Flood Management Options.

Ghana Statistical Services (2013). 2010 Population and Housing Census; summary report of final results. Ghana Statistical Service, Accra, Ghana.

Hosseni B. and Mehdiyar L. (2006). Applied Strategic Planning in Crisis Management, Aid and Save Learning and Reduction of Disaster Impacts, International conference of Crisis Management. 
Jha A. K., Bloch, R. and Lamond, J. (2012). Cities and Flooding a Guide to Integrated Urban Flood Risk Management for the 21st. Washington DC: The World Bank.

Karley, N.K. (2009). "Flooding and Physical Planning in Urban areas in West Africa: Situational Analysis of Accra, Ghana", Theoretical and Empirical Researches in Urban Management, 4(13), pp. 25-41

Kwang C, Osei EM (2017) Accra Flood Modelling through Application of Geographic Information Systems (GIS), Remote Sensing Techniques and Analytical Hierarchy Process. J Remote Sensing \& GIS 6: 191. doi:10.4172/2469-4134.1000191.

Lowery, B., Hickey, W.J., Arshad, M.A. and Lal, R. Soil water parameters and soil quality. In: (Madison W.I. (1996). Methods for assessing soil quality, 143-55.

Mulungeta, G., Ayngli, S., Daby, O.P., Gudyanga, F., Lucio, F. and Durrheem, R. (2007). Natural and Human-Induced Hazards Disasters in Sub-Saharan Africa, Science Plan. ICSU Regional Office for Africa.

Nicholls. N and Wong. K.K. (1990). Journal of Climate, 3: 163-170.

Prachansri S. (2007). "Analysis of soil and land cover parameters for flood hazard assessment: a case study of the Nam Chun watershed, Phetchabun, Thailand" Enschede, ITC.

Pramojanee. P, Tanavud. C, Yongcharlermchai. C and Navanugraha. C. (1997). An application of GIS for mapping of flood hazard and risk area in Nakorn Sri Thammarat Province, South of Thailand. In Proceedings of International Conference on Geo-Information for Sustainable Management, 198-207.

Smith, K. (2004). Environmental Hazards: Assessing Risk and Reducing Disaster, Routledge Publishers, New York

Uddin, K., Gurung, D. R., Giriraj, A., \& Shrestha, B. (2013). Application of remote sensing and GIS for flood hazard management: a case study from Sindh Province, Pakistan. American Journal of Geographic Information System, 2(1), 1-5.

Würtenberger, L., Bonzes, I.G, van Tilburg, X. (2011). Initiatives related to climate change in Ghana towards coordinating efforts. Netherlands: Energy Research Centre. 